\title{
Catalytic Synthesis of Cyclic Guanidines via Hydrogen Atom Transfer and Radical-Polar Crossover
}

\author{
Shunya Ohuchi, Hiroki Koyama, and Hiroki Shigehisa*, \\ Faculty of Pharmacy, Musashino University \\ 1-1-20 Shinmachi Nishitokyo-shi, Tokyo 202-8585, Japan
}

KEYWORDS. Hydrogen atom transfer, radical-polar crossover, cyclic guanidine, heterocycles

\begin{abstract}
Cyclic guanidines are found in many biologically active compounds and natural products. Further, the formation of the atypical 7-membered ring of cyclic guanidine remains challenging due to a lack of efficient preparation strategies and low yield. Herein, a catalytic synthetic method for cyclic guanidines was developed via transition-metal hydrogen atom transfer and radical-polar crossover. This mild and functional-group tolerant process enabled the cyclization of an alkenyl guanidines bearing common protective groups, such as $\mathrm{Cbz}$ and Boc groups. This powerful method not only provided typical 5- and 6-membered rings but also the atypical 7-membered ring. The derivatization of the products afforded various heterocycles. We also investigated the selective cyclization of mono-protected or hetero-protected (TFA and Boc) alkenyl guanidines and their further derivatizations.
\end{abstract}

Guanidine is an inherently effective basic motif. For instance, arginine, a series of amino acids, contains the guanidine motif and contributes to the expression of biological functions. ${ }^{1}$ Moreover, its cyclic form is present in potent bioactive compounds and natural products, ${ }^{2}$ such as saxioxin ${ }^{3}$ (blocker of voltage-gated sodium channels) and teixobactin 4 (an antibiotics for resistant bacteria) (Scheme 1). Because of these chemical and medicinal properties of cyclic guanidines, the development of a useful method for their synthesis has been of long-standing interest in organic synthesis., ${ }^{2,5}$ There are various methods for synthesizing cyclic guanidines, such as intramolecular displacement, ${ }^{6}$ halocyclization, ${ }^{7}$ and others. ${ }^{8}$ Metalcatalyzed processes were developed, including alkene hydroamination $(\mathrm{Ag}),{ }^{9}$ alkene carboamination $(\mathrm{Pd}),{ }^{10}$ alkene diamination (Pd), ${ }^{11}$ alkyne hydroamination (Ag, $\mathrm{Rh}),^{12}$ alkyne carboamination $(\mathrm{Pd}),{ }^{13} \mathrm{C}-\mathrm{H}$ amination $(\mathrm{Rh}),{ }^{14}$ cyclization via ( $\pi$-allyl) palladium intermediate, ${ }^{15}$ carbenylative amination (Pd). ${ }^{16}$ Both, traditional and metal-catalyzed methods have been used in the synthesis of complex natural products. ${ }^{17}$ Despite numerous examples of cyclic guanidine formation, the atypical and more challenging 7-membered ring, which is an undeveloped chemical space, has not been prepared efficiently. It is also noteworthy that potent drug candidates containing $7^{-}$ membered ring have been reported in recent years. ${ }^{18}$ Dodd and co-workers reported two examples of $7^{-}$ membered ring guanidines synthesized via halocyclization, however, to the best of our knowledge, there is significant potential to improve the yields (23\% and $21 \%) .7^{\mathrm{e}}$ Herein, we demonstrate a powerful, catalytic, Markovnikov-selective, and scalable hydroamination that affords cyclic guanidines via the transition-metal hydrogen atom transfer (TM-HAT) and radical-polar crossover (RPC).

Recently, TM-HAT catalytic systems have been used by many groups to facilitate various transformations of alkenes with excellent functional group tolerance. ${ }^{19} \mathrm{We}$ have previously reported the unique effect of $N$ fluorocollidinium salt on the TM-HAT system that enables the ionic process via the RPC mechanism, which led to further transformations developed by $\mathrm{us}^{20}$ and other groups. ${ }^{21}$ Encouraged by these reports, we envisioned that an alkenyl guanidine bearing a common and easily removable protective groups (carboxybenzyl $(\mathrm{Cbz})$ and or tert-butoxycarbonyl (Boc) could be cyclized via the TMHAT and RPC approach. The use of these common protective groups was not successful for hydroaminations nor similar transformations with different catalysis.9-10,11c Moreover, we assumed that the high reactivity based on the TM-HAT/RPC mechanism could efficiently form an unusual ring size of cyclic guanidines.

We initially chose to examine the 5-exo cyclization of alkenyl guanidine ra bearing two $\mathrm{Cbz}$ groups and obtained the desired cyclic guanidine $\mathbf{2 a}$ in $88 \%$ yield using previously developed reaction conditions: cobalt catalyst C1, $N$-fluoro-2,4,6-collidinium trifluoromethanesulfonate ( $\mathrm{Me}_{3} \mathrm{NFPY}$.OTf), and 1,1,3,3-tetramethyldisiloxane (Scheme 2, entry 1). When phenylsilane was used, the yield of 2 a decreased due to the formation of cyclic urea 3a (entry 2). Screening of various cobalt complexes ( $\mathbf{C}_{\mathbf{1}}-$ C3) revealed that the four tert-butyl groups were essential for acceptable conversion (entries $1,3,4$ ). We found that the previously developed complex $\mathbf{C}_{4}$ provided slightly better conversion than that of $\mathbf{C}_{\mathbf{1}}$ (entry 5). Replacing the 
counteranion of $\mathrm{Me}_{3} \mathrm{NFPY}$ salt with tetrafluoroborate $\left(\mathrm{BF}_{4}\right)$ or hexafluorophosphate $\left(\mathrm{PF}_{6}\right)$ did not improve the efficiency of the reaction (entries 6 and 7 ). Moreover, 841 $\mathrm{mg}(2.30 \mathrm{mmol})$ of $2 \mathrm{a}$ could be synthesized from $1.02 \mathrm{~g}$ of 1a $(82 \%)$.

Scheme 1 (a) Representative Examples of Natural Products bearing Cyclic Guanidine, (b) Representative Methods affording Cyclic Guanidine, and (c) This Work: Synthesis of Cyclic Guanidine by the TM-HAT and RPC Concept

(a) Bioactive compounds bearing cyclic guanidine

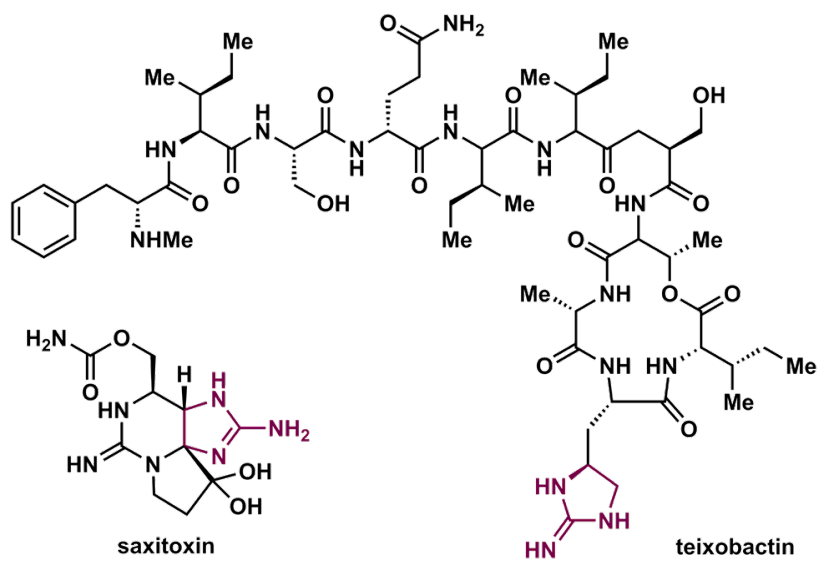

(b) Representative examples of cyclic guanidine synthesis

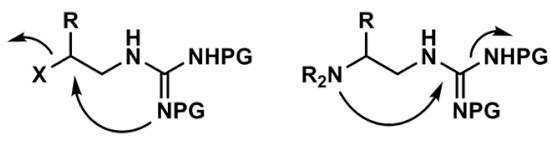

intramolecular displacement

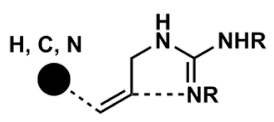

alkene hydroamination $(\mathrm{Ag})$ alkene carboamination $(\mathrm{Pd})$ alkene diamination (Pd)

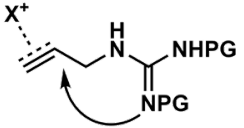

alkene halocyclization alkyne halocyclization

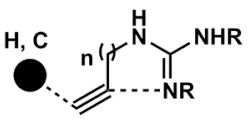

alkyne hydroamination (Ag: 5-exo, Rh: 6-endo)

alkyne carboamination $(\mathrm{Pd})$

(c) This work: synthesis of cyclic guanidines by TM-HAT \& RPC concept
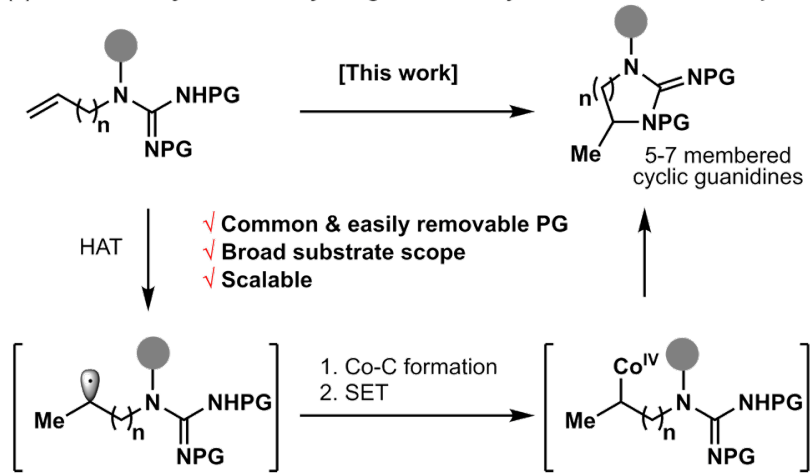

With the optimal conditions, we next briefly examined the scope of the substituted alkenyl guanidine forming 5membered ring products $(\mathbf{1 b}-\mathbf{1 g})$ (Scheme 3$)$. The substrates bearing the electron-withdrawing chloro $(\mathbf{1 b})$ or electron-donating methoxy (1c) in the $p$-position of the aniline unit gave $\mathbf{2 b}$ and $\mathbf{2 c}$ in good yields, respectively. The dimethylated product $\mathbf{2 d}$ was also synthesized from the disubstituted alkenyl guanidine $\mathbf{1 d}$ in $80 \%$ yield together with a hydroxylated compound ( $9 \%)$. The yields were also excellent for the substrates, including methylamine (1e), benzylamine (1f), and phenethylamine (1g).

Encouraged by this result, we next applied the same concept to form rings. Other than those with 5-members. We discovered that 6-exo and 7-exo cyclizations were possible under the same reaction conditions ( $\mathbf{2 h}$ and $\mathbf{2 i}$ ) (Scheme 4). The yields of $\mathbf{2 h}$ using $\mathbf{C}_{\mathbf{4}}$ and $\mathbf{C}_{\mathbf{1}}$ were identical, but $\mathbf{C}_{4}$ proved to be advantageous for producing $2 \mathbf{i}$. Although this method was ineffective for the formation of 8membered guanidine $\mathbf{2 j}$, we focused on the preparation of various 7-membered guanidines.

Scheme 2. Optimization of Reaction Condition

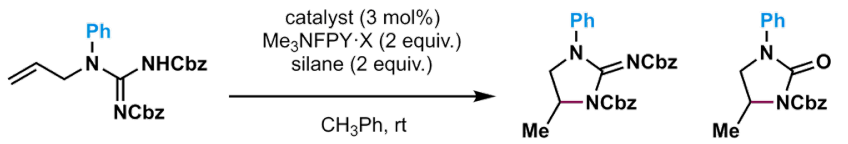

\begin{tabular}{|c|c|c|c|c|}
\hline entry & cat. & $x$ & silane & $2 a(\%)^{a}$ \\
\hline 1 & C1 & OTf & $\left(\mathrm{Me}_{2} \mathrm{SiH}\right)_{2} \mathrm{O}$ & 88 \\
\hline 2 & C1 & OTf & $\mathrm{PhSiH}_{3}$ & $59(+25 \% 3 a)$ \\
\hline 3 & C2 & OTf & $\left(\mathrm{Me}_{2} \mathrm{SiH}\right)_{2} \mathrm{O}$ & 74 \\
\hline 4 & C3 & OTf & $\left(\mathrm{Me}_{2} \mathrm{SiH}\right)_{2} \mathrm{O}$ & 32 \\
\hline 5 & $\mathrm{C} 4$ & OTf & $\left(\mathrm{Me}_{2} \mathrm{SiH}\right)_{2} \mathrm{O}$ & $90,84^{\mathrm{b}}, 82^{\mathrm{c}}$ \\
\hline 6 & $\mathrm{C} 4$ & $\mathrm{BF}_{4}$ & $\left(\mathrm{Me}_{2} \mathrm{SiH}\right)_{2} \mathrm{O}$ & 76 \\
\hline 7 & $\mathrm{C} 4$ & $\mathrm{PF}_{6}$ & $\left(\mathrm{Me}_{2} \mathrm{SiH}\right)_{2} \mathrm{O}$ & 83 \\
\hline
\end{tabular}
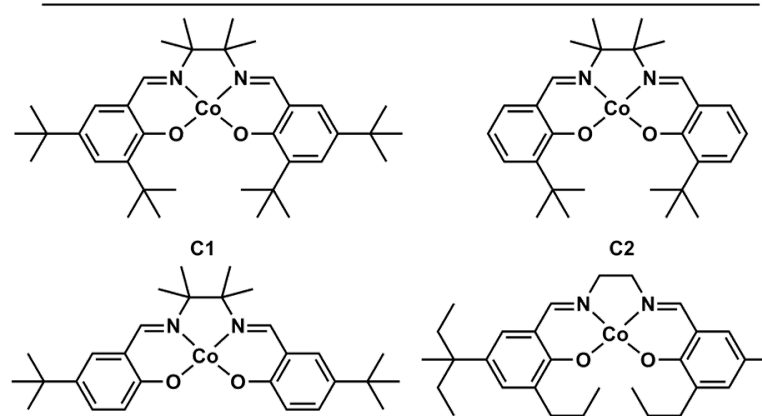

C2 $3 a$

C3

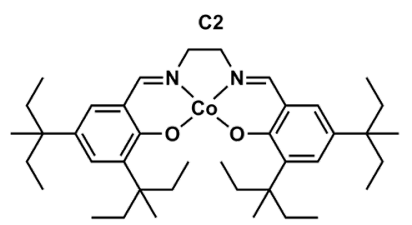

C4

Conditions: alkenyl guanidine (o.1 mmol), catalyst (o.003 $\mathrm{mmol}$ ), $\mathrm{Me}_{3} \mathrm{NFPY} \cdot \mathrm{X}$ (0.2 mmol), silane (o.2 mmol), $\mathrm{CH}_{3} \mathrm{Ph}$ (1.0 $\mathrm{mL}$ ), room temperature, $20 \mathrm{~h}$. ${ }^{a} \mathrm{NMR}$ yield using $1,4^{-}$ bis(trifluoromethyl)benzene as the internal standard.

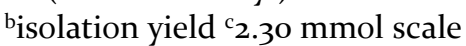

Scheme 3. Scope of Alkenyl Guanidines Affording 5Membered Ring Products ${ }^{\mathrm{a}}$ 

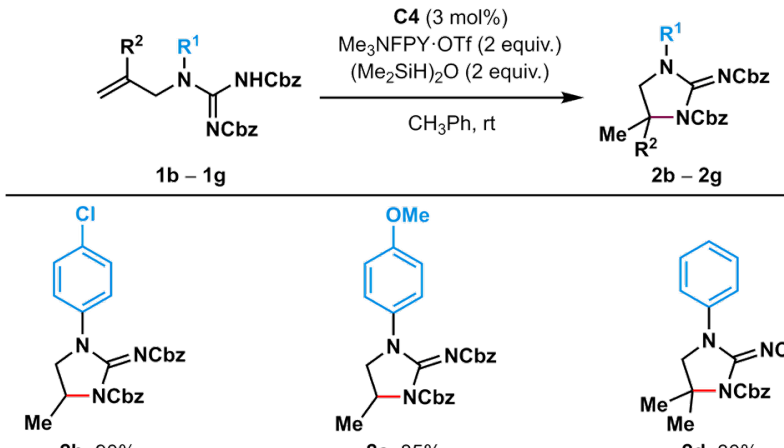

$2 b-2 g$

2b, $90 \%$
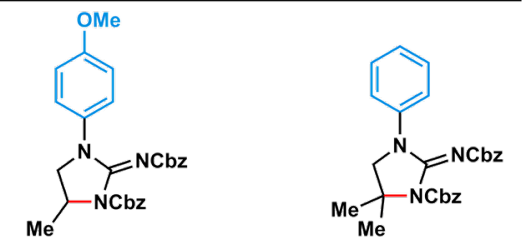

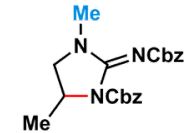

2e, $90 \%$

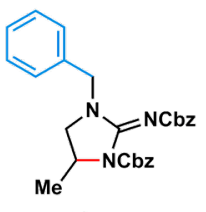

2f, $73 \%$

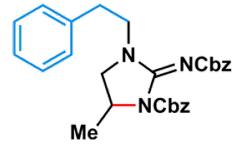

2g, $94 \%$

Conditions: alkenyl guanidine (o.1 mmol), catalyst (o.oo3 mmol), $N$-fluorocollidinium trifluoromethanesulfonate (o.2 mmol), 1,1,3,3-tetramethyldisiloxane (o.2 mmol), $\mathrm{CH}_{3} \mathrm{Ph}(1.0 \mathrm{~mL})$, room temperature, $20 \mathrm{~h}$. aisolation yield

Scheme 4. Scope of Alkenyl Guanidines Affording Products of 6- and 7-Membered Rings ${ }^{\mathrm{a}}$

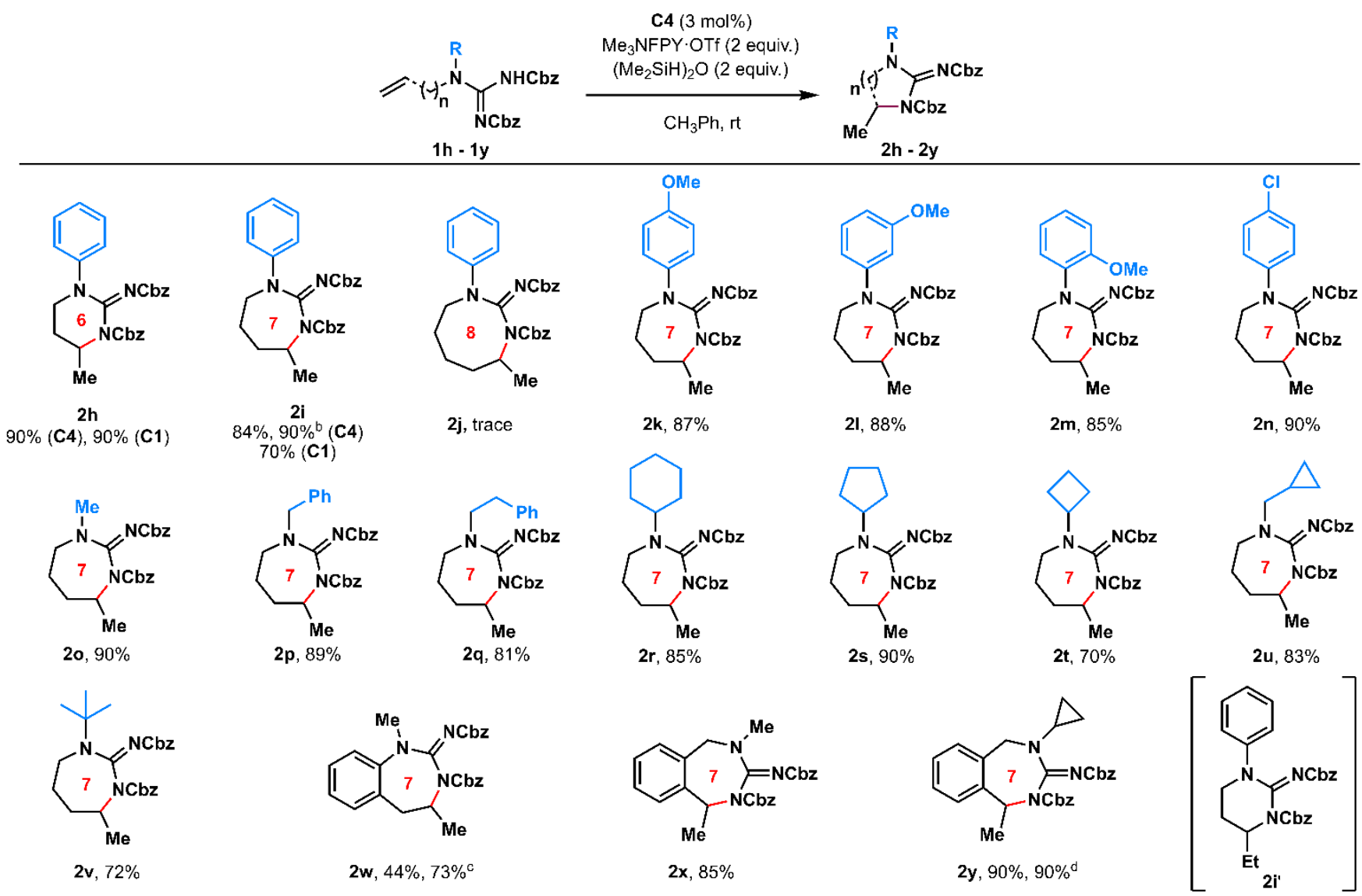

Conditions: alkenyl guanidine $(0.1 \mathrm{mmol}), \mathbf{C}_{\mathbf{4}}(0.003 \mathrm{mmol}), \mathrm{N}$-fluorocollidinium trifluoromethanesulfonate $(0.2 \mathrm{mmol})$, 1,1,3,3-tetramethyldisiloxane $(0.2 \mathrm{mmol}), \mathrm{CH}_{3} \mathrm{Ph}(1.0 \mathrm{~mL})$, room temperature, $20 \mathrm{~h}$. ${ }^{\text {a }}$ isolation yield ${ }^{\mathrm{b}} 3.00 \mathrm{mmol}$ scale ${ }^{\mathrm{c}} 9$ mol\% of $\mathbf{C}_{4}$ was used. ${ }^{\mathrm{d}} \mathbf{4} .13 \mathrm{mmol}$ scale

We next examined the electronic and steric effects using substrates with aniline units bearing electron-donating or electron-withdrawing groups in different positions on the aniline ring. We found no significant differences when using substrates $\mathbf{1 k}$ - in that gave the corresponding 4methoxy (2k), 3-methoxy (2l),2-methoxy (2m), and 4chloro (2n) products. Again, replacing the aniline unit with an aliphatic amine such as methylamine, benzyla- 
mine, and phenethylamine, resulted in comparable yields $(2 \mathbf{0}-\mathbf{2 q})$. The products bearing more hindered amine such as cyclohexylamine (2r), cyclopentylamine (2s), and tert-butylamine (2v), were prepared in $72-90 \%$ yields. Strained carbocycles such as the cyclobutyl (2s) and cyclopropylmethyl groups (2u) were tolerated in this reaction condition. Moreover, we could prepare benzocyclic guanidines $(\mathbf{2} \mathbf{w}-\mathbf{2 y})$ in $73-90 \%$ yields using the same method. We reinvestigated the scalability of this reaction using $1.42 \mathrm{~g}(3.00 \mathrm{mmol})$ of $\mathbf{1 i}$ and obtained $2 \mathbf{i}$ in $90 \%$ isolation yield. This scale-up experiment enabled the isolation and structural determination of a small amount of byproduct $2 \mathbf{i}^{\prime}(6 \%)$, probably produced via the $1,2-\mathrm{H}$ shift of the alkylCo(IV) intermediate. We also prepared $1.80 \mathrm{~g}$ of benzocyclic 2y in 90\% yield, together with a small amount of complex byproduct mixtures, from $2.00 \mathrm{~g}$ (4.13 mmol) of $1 y$.

We also examined cyclizations using trisubstituted alkenyl guanidines (Scheme 5). Although the formation of the 6-membered cyclic guanidine 5a was amenable, the yield was less than moderate due to a side reaction (hydroarylation) affording $\mathbf{5} \mathbf{b}$, which had also been reported by our group. ${ }^{\text {od }}$ The use of $\mathbf{C}_{\mathbf{1}}$ did not improve the yield of 5a (14\%). 7-membered cyclic guanidine $7 \mathbf{a}$ was also obtained; however, the byproducts $\mathbf{7 b}$ and $\mathbf{7 c}$ were also formed in small amounts.

Scheme 5. Cyclization of Trisubstituted Alkenyl Guanidines
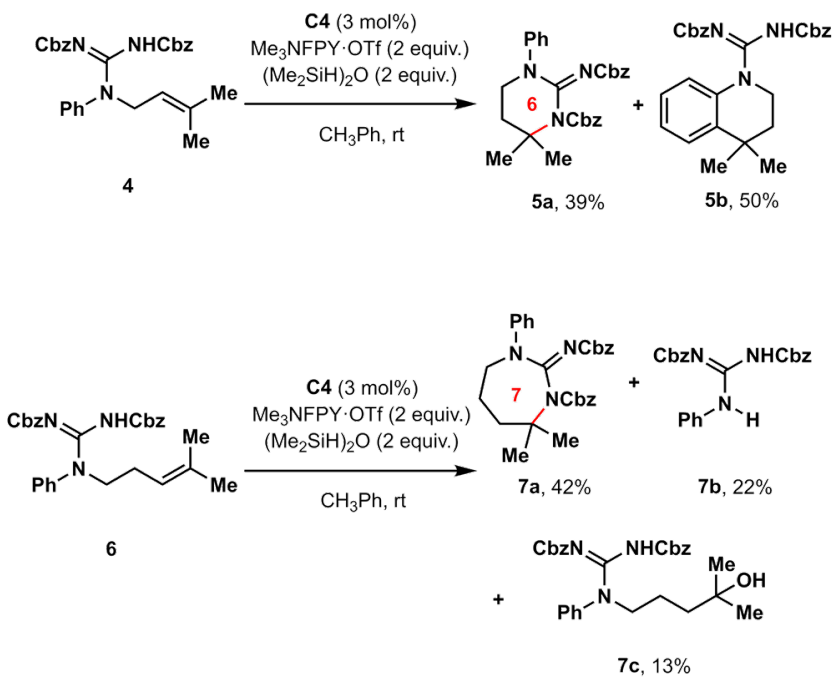

As expected, replacing the two Cbz groups of $1 \mathrm{a}$ with the Boc groups, another common protective group, resulted in a $90 \%$ yield of the 5-membered cyclic guanidine 9a (Scheme 6). The products containing methylamine 9e and benzylamine $\mathbf{9} \mathbf{f}$ were also synthesized in good yields. It should be noted that ge could not been synthesized by the previously reported hydroamination method. ${ }^{9}$ 7- $^{-}$ membered cyclic guanidine $\mathbf{9 i}$ was obtained in $75 \%$ yield together with the alkene-isomerized byproduct and 6membered cyclic guanidine similar to $2 \mathbf{i}^{\prime}$. Moreover, the product 9p bearing a benzylamine unit was obtained in comparable yield.
Scheme 6. Cyclization of Alkenyl Guanidines Bearing Boc group $^{\mathrm{a}}$
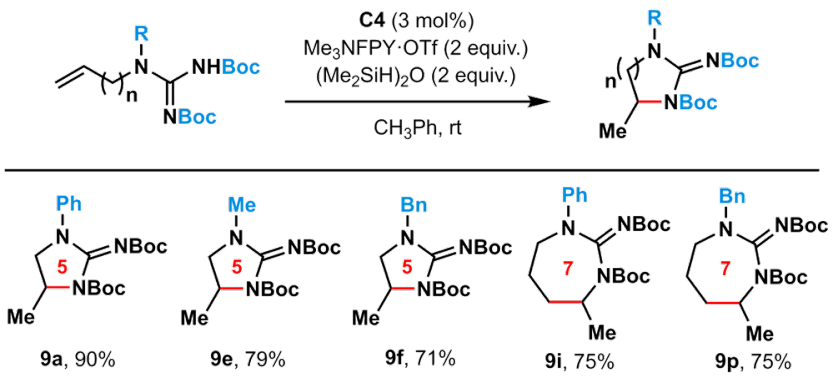

Conditions: alkenyl guanidine ( $0.5 \mathrm{mmol})$, catalyst (0.015 mmol), $N$-fluorocollidinium trifluoromethanesulfonate (1.0 mmol), 1,1,3,3-tetramethyldisiloxane (1.0 mmol), $\mathrm{CH}_{3} \mathrm{Ph}(5.0 \mathrm{~mL})$, room temperature, $20 \mathrm{~h}$. aisolation yield

Scheme 7. Derivatization of Cyclic Guanidines ${ }^{\mathrm{a}}$
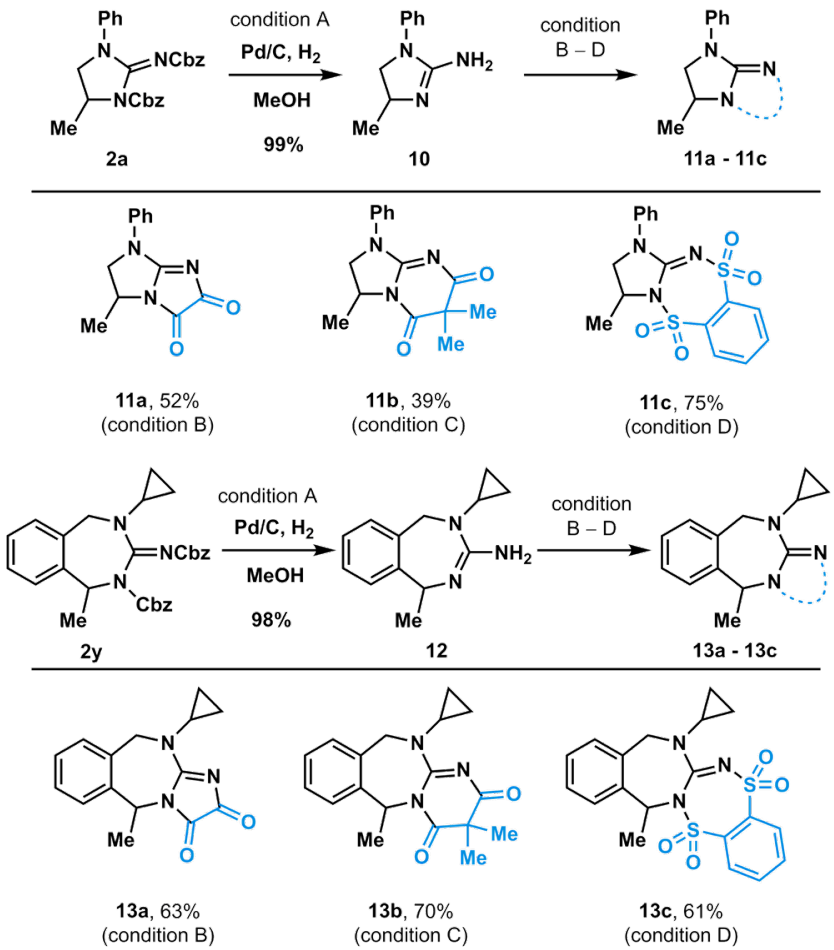

(A) $\mathrm{Pd} / \mathrm{C}, \mathrm{H}_{2}, \mathrm{MeOH}, \mathrm{rt}, \mathrm{l}$ h (B) oxalyl chloride (2.o equiv.), $\mathrm{NEt}_{3}$ (5.0 equiv.), $\mathrm{CH}_{2} \mathrm{Cl}_{2}$ (o.03 M), rt, $12 \mathrm{~h}$ (C) dimethylmalonyl dichloride (2.0 equiv.), $\mathrm{NEt}_{3}$ (5.0 equiv.), $\mathrm{CH}_{2} \mathrm{Cl}_{2}$ (0.03 M), rt, $12 \mathrm{~h}$ (D) 1,2-benzenedisulfonyl dichloride (2.0 equiv.), $\mathrm{NEt}_{3}$ (5.0 equiv.), $\mathrm{CH}_{2} \mathrm{Cl}_{2}$ (0.03 M), rt, 12 $\mathrm{h}$

In order to demonstrate the synthetic potential of the cyclic guanidines prepared by this method, 5-membered cyclic guanidine $2 \mathbf{a}$ was subjected to deprotection and diversification (Scheme 7). The conventional palladiumcatalyzed hydrogenation of $\mathbf{2 a}$ produced free cyclic guanidine 10 almost quantitatively, which was further transformed into bicyclic guanidines $\mathbf{1 1}$ a and $\mathbf{1 1 b}$, and tricyclic guanidine 110 in moderate yields. We also derivatized 7membered guanidine $\mathbf{2 y}$ in the same manner to produce tricyclic guanidines $\mathbf{1 3 a}$ and $\mathbf{1 3 b}$ and tetracyclic $\mathbf{1 3 \mathbf { C }}$ in moderate yields. 
For comparison, we performed cobalt catalysis with mono-Ts guanidine $\mathbf{1 4}$, which had been successfully used in hydroamination reactions (Scheme 8). To our surprise, we found that the product selectivity was clearly complementary. It was reported that $\mathbf{1 5}$ was selectively obtained under Wolfe's conditions, ${ }^{9}$ whereas we observed a high-polar compound (assumed as 16INT), which could not be purified by silica gel chromatography. The formylation of this crude mixture enabled the isolation and structural determination as $\mathbf{1 6}$. Thus, this result indicates that our reactive nitrogen atom of the guanidine moiety is different that of Wolfe's.

Scheme 8. Selective Cyclization of Mono-protected or Hetero-protected (TFA (trifluoroacetyl) and Boc) Alkenyl Guanidine and Further Derivatizations.

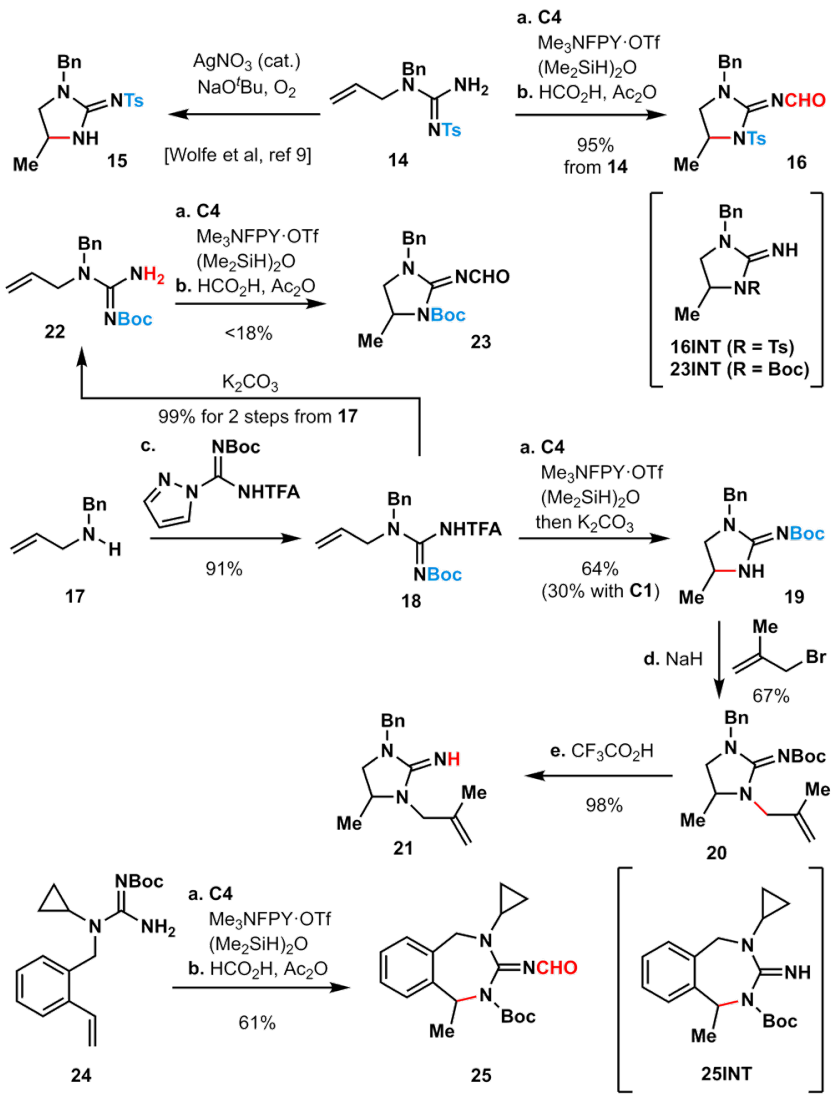

(a) $\mathbf{C}_{4}, \mathrm{Me}_{3} \mathrm{NFPY}$.OTf, $\left(\mathrm{Me}_{2} \mathrm{SiH}\right)_{2} \mathrm{O}, \mathrm{CH}_{3} \mathrm{Ph}, \mathrm{rt}, 2 \mathrm{o} \mathrm{h}$ (b) $\mathrm{HCO}_{2} \mathrm{H}, \mathrm{Ac}_{2} \mathrm{O}, \mathrm{NEt}_{3}, \mathrm{CH}_{2} \mathrm{Cl}_{2}$, rt 3 h (c) $N$-Boc-N'-TFApyrazole-1-carboxamidine, THF, rt, 3 h (d) NaH, 3-bromo2-methylpropene, DMF, rt, $1 \mathrm{~h}$ (e) trifluoroacetic acid, $\mathrm{CH}_{2} \mathrm{Cl}_{2}$, rt $3 \mathrm{~h}$

Toward further examination of the scope of guanidine, we prepared alkenyl guanidines 18 and 22 by Baran's method. ${ }^{17 \mathrm{~h}}$ The cyclization of Boc-TFA (trifluoroacetyl) guanidine $\mathbf{1 8}$, followed by treatment with potassium carbonate (to remove remaining TFA group), selectively produced $\mathbf{1 9}$ in $64 \%$ yield. This yield was not improved using $C_{1}$ instead of $\mathbf{C}_{4}$. The alkylation of cyclic guanidine $\mathbf{1 9}$ and its Boc deprotection affording 21 were both amenable by conventional methods. On the other hand, the cyclization of mono-Boc guanidine 22 yielded a high-polar compound (assumed as 23INT). This structure was clearly elucidated by the formylation to be 23. Unsfortunately, the yield of Boc-guanidine 23 was much lower than that of Tsguanidine $\mathbf{1 6}$. This cyclization/formylation sequence also afforded 25 in $61 \%$ yield, although the cyclization of the corresponding Boc-TFA guanidine resulted in a complex product mixture.

In summary, we developed a catalytic, Markovnikovselective, scalable method for synthesizing cyclic guanidines using a TM-HAT/RPC approach. We efficiently constructed 5, 6, and 7-membered cyclic guanidines bearing common and easily removable $\mathrm{Cbz}$ or Boc under mild conditions. This unique and powerful method enabled the expansion of the chemical space of atypical 7-membered cyclic guanidines. Further diversifications of the products through cobalt catalysis led to various heterocycles. The investigations using alkenyl guanidines bearing the mono-Boc or Boc-TFA protective groups revealed the selective product formation and expansion of accessible cyclic guanidines by further transformations. We are currently investigating enantioselective variants using a chiral cobalt catalyst.

\section{ASSOCIATED CONTENT}

Experimental procedures and analytical data $\left({ }^{1} \mathrm{H}\right.$ and ${ }^{13} \mathrm{C}$ NMR) for all new compounds. This material is available free of charge via the Internet at http://pubs.acs.org.

\section{AUTHOR INFORMATION}

\section{Corresponding Author}

*Email: cgehisa@musashino-u.ac.jp

\section{Funding Sources}

JSPS KAKENHI Grant number ${ }_{17} \mathrm{~K}_{15426}$

The Takeda Science Foundation

The research foundation for pharmaceutical sciences

\section{ACKNOWLEDGMENT}

We thank Prof. Kou Hiroya (Musashino University) for our liberal research environment.

\section{REFERENCES}

(1) (a) Adina-Zada, A.; Sereeruk, C.; Jitrapakdee, S.; Zeczycki, T. N.; St Maurice, M.; Cleland, W. W.; Wallace, J. C.; Attwood, P. V., Roles of Arg427 and Arg472 in the binding and allosteric effects of acetyl CoA in pyruvate carboxylase. Biochemistry 2012, 51, 8208-8217. (b) Derbel, N.; Clarot, I.; Mourer, M.; Regnoufde-Vains, J. B.; Ruiz-Lopez, M. F., Intramolecular interactions versus hydration effects on p-guanidinoethyl-phenol structure and pKa values. J. Phys. Chem. A 2012, 116, 9404-9411. (c) Chen, X.; Guo, Y.; Jia, G.; Zhao, H.; Liu, G.; Huang, Z., Arginine Promotes Slow Myosin Heavy Chain Expression via Akirin2 and the AMPActivated Protein Kinase Signaling Pathway in Porcine Skeletal Muscle Satellite Cells. J. Agric. Food Chem. 2018, 66, 4734-4740. (d) Brezina, K.; Duboue-Dijon, E.; Palivec, V.; Jiracek, J.; Krizek, T.; Viola, C. M.; Ganderton, T. R.; Brzozowski, A. M.; Jungwirth, P., Can Arginine Inhibit Insulin Aggregation? A Combined Protein Crystallography, Capillary Electrophoresis, and Molecular Simulation Study. J. Phys. Chem. B 2018, 122, 10069-10076. 
(2) Berlinck, R. G. S.; Bertonha, A. F.; Takaki, M.; Rodriguez, J. P. G., The chemistry and biology of guanidine natural products. Nat. Prod. Rep. 2017, 34, 1264-1301.

(3) Thottumkara, A. P.; Parsons, W. H.; Du Bois, J., Saxitoxin. Angew. Chem. Int. Ed. 2014, 53, 5760-5784.

(4) Ling, L. L.; Schneider, T.; Peoples, A. J.; Spoering, A. L.; Engels, I.; Conlon, B. P.; Mueller, A.; Schäberle, T. F.; Hughes, D. E.; Epstein, S.; Jones, M.; Lazarides, L.; Steadman, V. A.; Cohen, D. R.; Felix, C. R.; Fetterman, K. A.; Millett, W. P.; Nitti, A. G.; Zullo, A. M.; Chen, C.; Lewis, K., A new antibiotic kills pathogens without detectable resistance. Nature 2015, 517, 455459.

(5) (a) Zhang, W.-X.; Xu, L.; Xi, Z., Recent development of synthetic preparation methods for guanidines via transition metal catalysis. Chem. Commun. 2015, 51, 254-265. (b) Lemrová, B.; Soural, M., Synthetic Strategies for Preparing Bicyclic Guanidines. Eur. J. Org. Chem. 2015, 2015, 1869-1886.

(6) (a) Kim, H.-O.; Mathew, F.; Ogbu, C., A Convenient Synthesis of Disubstituted Guanidines via the Mitsunobu Protocol. Synlett 1999, 1999, 193-194. (b) Sanière, L.; Leman, L. c.; Bourguignon, J.-J.; Dauban, P.; Dodd, R. H., Iminoiodane mediated aziridination of $\alpha$-allylglycine: access to a novel rigid arginine derivative and to the natural amino acid enduracididine. Tetrahedron 2004, 60, 5889-5897. (c) Benohoud, M.; Leman, L.; Cardoso, S. H.; Retailleau, P.; Dauban, P.; Thierry, J.; Dodd, R. H., Total synthesis and absolute configuration of the natural amino acid tetrahydrolathyrine. J. Org. Chem. 2009, 74, 53315336. (d) O’Donovan, D. H.; Rozas, I., New methods for the preparation of aryl 2-iminoimidazolidines. Tetrahedron Lett. 2012 53, 4532-4535. (e) Buck, M. L.; Evans, D. M.; Evans, V. A.; Herkt, D.; Sharp, H.; Hollinshead, J.; Mitschang, F.; Murphy, P. J.; Nash, R. J.; Wenbourne, J., A synthesis of tiruchanduramine and a reinvestigation of its glycosidase inhibitory activity. Tetrahedron 2017, 73, 4545-4548. (f) Imaoka, T.; Iwata, M.; Nagasawa, K., Synthesis of a Quaternary $N, N^{\prime}$-Aminal-Containing A-E Ring System of Palau'amine via an Enamide-Type Overman Rearrangement Reaction. Eur. J. Org. Chem. 2018, 2018, 25722578 .

(7) (a) Watanabe, M.; Okada, H.; Teshima, T.; Noguchi, M.; Kakehi, A., A facile and regio- and stereo-selective preparation of bicyclic guanidines by iodocyclization of 3-(alk-2-enyl)-2(substituted amino)-1-imidazolin-4-ones. Tetrahedron 1996, 52, 2827-2838. (b) Chern, J. W.; Tao, P. L.; Wang, K. C.; Gutcait, A.; Liu, S. W.; Yen, M. H.; Chien, S. L.; Rong, J. K., Studies on quinazolines and 1,2,4-benzothiadiazine 1,1-dioxides. 8.1, 2 synthesis and pharmacological evaluation of tricyclic fused quinazolines and 1,2,4-benzothiadiazine 1,1-dioxides as potential alpha1-adrenoceptor antagonists. J. Med. Chem. 1998, 41, 31283141. (c) Hirota, S.; Kato, R.; Suzuki, M.; Soneta, Y.; Otani, T.; Saito, T., Synthesis of Diazaheterocyclic Ring-Fused 1,2,4Benzothiadiazine 1,1-Dioxides by a Sequential Aza-Wittig/NHAddition Cyclization/Nucleophilic Ring-Closure Methodology with $N$-Alkenyl-2-carbodiimidobenzenesulfonamides as Key Intermediates. Eur. J. Org. Chem. 2008, 2008, 2075-2083. (d) Al Shuhaib, Z.; Davies, D. H.; Dennis, M.; Evans, D. M.; Fletcher, M. D.; Franken, H.; Hancock, P.; Hollinshead, J.; Jones, I.; Kähm, K.; Murphy, P. J.; Nash, R.; Potter, D.; Rowles, R., Iodocyclisations reactions of Boc- and Cbz-protected $\mathrm{N}$ allylguanidines. Tetrahedron 2014, 70, 4412-4419. (e) Daniel, M.; Blanchard, F.; Nocquet-Thibault, S.; Cariou, K.; Dodd, R. H., Halocyclization of Unsaturated Guanidines Mediated by Koser's Reagent and Lithium Halides. J. Org. Chem. 2015, 80, 1062410633. (f) Nishikawa, T.; Sawayama, Y., Bromocyclization of Alkynyl Guanidine: A New Approach to the Synthesis of Cyclic Guanidines of Saxitoxin. Synlett 2011, 2011, 651-654. (g) Fedoseev, P.; Sharma, N.; Khunt, R.; Ermolat'ev, D. S.; Van der Eycken, E. V., Iodine-mediated regioselective guanylation- amination of propargylamines towards the synthesis of diversely substituted 2-aminoimidazoles. RSC Adv. 2016, 6, 75202-75206.

(8) (a) Huber, D.; Leclerc, G.; Ehrhardt, J. D.; Andermann, G., The 3,4-dimethoxybenzyl group: A protective group for new 2imino-imidazolidine derivates. Tetrahedron Lett. 1987, 28, 64536456. (b) Shipman, M.; Nalli, S.; Clarkson, G.; Franklin, A.; Bellone, G., Iminophosphorane-Mediated Synthesis of Cyclic Guanidines: Application to the Synthesis of a Simplified NA22598A1 Analogue. Synlett 2008, 2008, 2339-2341. (c) Mailyan, A. K.; Young, K.; Chen, J. L.; Reid, B. T.; Zakarian, A., Stereoselective Synthesis of Cyclic Guanidines by Directed Diamination of Unactivated Alkenes. Org. Lett. 2016, 18, 55325535. (d) Rao Kovvuri, V. R.; Xue, H.; Romo, D., Generation and Reactivity of 2-Amido-1,3-diaminoallyl Cations: Cyclic Guanidine Annulations via Net $(3+2)$ and $(4+3)$ Cycloadditions. Org. Lett. 2020, 22, 1407-1413.

(9) Garlets, Z. J.; Silvi, M.; Wolfe, J. P., Synthesis of Cyclic Guanidines via Silver-Catalyzed Intramolecular Alkene Hydroamination Reactions of $N$-Allylguanidines. Org. Lett. 2016, 18, 2331-2334.

(10) (a) Zavesky, B. P.; Babij, N. R.; Fritz, J. A.; Wolfe, J. P., Synthesis of cyclic guanidines via Pd-catalyzed alkene carboamination. Org. Lett. 2013, 15, 5420-5423. (b) Peterson, L. J.; Luo, J.; Wolfe, J. P., Synthesis of Cyclic Guanidines Bearing $\mathrm{N}$-Arylsulfonyl and $\mathrm{N}$-Cyano Protecting Groups via Pd-Catalyzed Alkene Carboamination Reactions. Org. Lett. 2017, 19, 2817 2820.

(11) (a) Hövelmann, C. H.; Streuff, J.; Brelot, L.; Muñiz, K., Direct synthesis of bicyclic guanidines through unprecedented palladium(ii) catalysed diamination with copper chloride as oxidant. Chem. Commun. 2008, 2334-2336. (b) Zhao, B.; Du, H.; Shi, Y., Cu(I)-Catalyzed Cycloguanidination of Olefins. Org. Lett. 2008, 10, 1087-1090. (c) Peterson, L. J.; Kirsch, J. K.; Wolfe, J. P., Pd-Catalyzed Alkene Diamination Reactions of Nitrogen Electrophiles: Synthesis of Cyclic Guanidines and Ureas Bearing Dialkylaminomethyl Groups. Org. Lett. 2018, 20, 3513-3517.

(12) (a) Gainer, M. J.; Bennett, N. R.; Takahashi, Y.; Looper, R. E., Regioselective rhodium(II)-catalyzed hydroaminations of propargylguanidines. Angew. Chem. Int. Ed. 2011, 50, 684-687. (b) Kwon, K. H.; Serrano, C. M.; Koch, M.; Barrows, L. R.; Looper, R. E., Synthesis of bicyclic guanidines via cascade hydroamination/Michael additions of mono- $N$ acryloylpropargylguanidines. Org. Lett. 2014, 16, 6048-6051.

(13) Zavesky, B. P.; Babij, N. R.; Wolfe, J. P., Synthesis of substituted 2-aminoimidazoles via Pd-catalyzed alkyne carboamination reactions. Application to the synthesis of preclathridine natural products. Org. Lett. 2014, 16, 4952-4955.

(14) Kim, M.; Mulcahy, J. V.; Espino, C. G.; Du Bois, J., Expanding the substrate scope for $\mathrm{C}-\mathrm{H}$ amination reactions: oxidative cyclization of urea and guanidine derivatives. Org. Lett. 2006, 8, 1073-1076.

(15) (a) Buchi, G.; Rodriguez, A. D.; Yakushijin, K., Syntheses of (+/-)-alchorneine and (+/-)-isoalchorneine. J. Org. Chem. 1989, 54, 4494-4496. (b) Butler, D. C.; Inman, G. A.; Alper, H., Room temperature ring-opening cyclization reactions of 2vinylaziridines with isocyanates, carbodiimides, and isothiocyanates catalyzed by. J. Org. Chem. 2000, 65, 5887-5890. (16) Kitamura, M.; Yuasa, R.; Van Vranken, D. L., Synthesis of the cyclic prenylguanidine nitensidine E using a palladiumcatalyzed carbenylative amination. Tetrahedron Lett. 2015, 56, 3027-3031

(17) (a) Mulcahy, J. V.; Du Bois, J., A stereoselective synthesis of (+)-gonyautoxin 3. J. Am. Chem. Soc. 2008, 130, 12630-12631. (b) Su, S.; Rodriguez, R. A.; Baran, P. S., Scalable, stereocontrolled total syntheses of (+/-)-axinellamines A and B. $J$. Am. Chem. Soc. 2011, 133, 13922-13925. (c) Perl, N. R.; Ide, N. D.; Prajapati, S.; Perfect, H. H.; Duron, S. G.; Gin, D. Y., 
Annulation of thioimidates and vinyl carbodiimides to prepare 2aminopyrimidines, competent nucleophiles for intramolecular alkyne hydroamination. Synthesis of (-)-crambidine. J. Am. Chem. Soc. 2010, 132, 1802-1803. (d) Bhonde, V. R.; Looper, R. E., A stereocontrolled synthesis of (+)-saxitoxin. J. Am. Chem. Soc. 2011, 133, 20172-20174. (e) Gibbons, J. B.; Gligorich, K. M.; Welm, B. E.; Looper, R. E., Synthesis of the reported structures for kealiinines B and C. Org. Lett. 2012, 14, 4734-4737. (f) Rodriguez, R. A.; Barrios Steed, D.; Kawamata, Y.; Su, S.; Smith, P. A.; Steed, T. C.; Romesberg, F. E.; Baran, P. S., Axinellamines as broad-spectrum antibacterial agents: scalable synthesis and biology. J. Am. Chem. Soc. 2014, 136, 15403-15413. (g) Gibbons, J. B.; Salvant, J. M.; Vaden, R. M.; Kwon, K. H.; Welm, B. E.; Looper, R. E., Synthesis of Naamidine A and Selective Access to $N^{2}$-Acyl-2-aminoimidazole Analogues. J. Org. Chem. 2015, 80, 10076-10085. (h) Tian, M.; Yan, M.; Baran, P. S., 11-Step Total Synthesis of Araiosamines. J. Am. Chem. Soc. 2016, 138, 1423414237.

(18) (a) Ikegashira, K.; Oka, T.; Hirashima, S.; Noji, S.; Yamanaka, H.; Hara, Y.; Adachi, T.; Tsuruha, J.-I.; Doi, S.; Hase, Y.; Noguchi, T.; Ando, I.; Ogura, N.; Ikeda, S.; Hashimoto, H., Discovery of Conformationally Constrained Tetracyclic Compounds as Potent Hepatitis C Virus NS5B RNA Polymerase Inhibitors. J. Med. Chem. 2006, 49, 6950-6953. (b) Ganguly, A. K.; Alluri, S. S.; Wang, C.-H.; Antropow, A.; White, A.; Caroccia, D.; Biswas, D.; Kang, E.; Zhang, L.-K.; Carroll, S. S.; Burlein, C.; Fay, J.; Orth, P.; Strickland, C., Structural optimization of cyclic sulfonamide based novel HIV-1 protease inhibitors to picomolar affinities guided by X-ray crystallographic analysis. Tetrahedron 2014, 70, 2894-2904. (c) Gerasyuto, A. I.; Arnold, M. A.; Wang, J.; Chen, G.; Zhang, X.; Smith, S.; Woll, M. G.; Baird, J.; Zhang, N.; Almstead, N. G.; Narasimhan, J.; Peddi, S.; Dumble, M.; Sheedy, J.; Weetall, M.; Branstrom, A. A.; Prasad, J. V. N.; Karp, G. M., Discovery and Optimization of Indolyl-Containing 4Hydroxy-2-Pyridone Type II DNA Topoisomerase Inhibitors Active against Multidrug Resistant Gram-negative Bacteria. $J$. Med. Chem. 2018, 61, 4456-4475. (d) Lopez-Tapia, F.; Lou, Y.; Brotherton-Pleiss, C.; Kuglstatter, A.; So, S.-S.; Kondru, R., A potent seven-membered cyclic BTK (Bruton's tyrosine Kinase) chiral inhibitor conceived by structure-based drug design to lock its bioactive conformation. Bioorg. Med. Chem. Lett. 2019, 29, 1074-1078. (e) Heightman, T. D.; Callahan, J. F.; Chiarparin, E.; Coyle, J. E.; Griffiths-Jones, C.; Lakdawala, A. S.; McMenamin, R.; Mortenson, P. N.; Norton, D.; Peakman, T. M.; Rich, S. J.; Richardson, C.; Rumsey, W. L.; Sanchez, Y.; Saxty, G.; Willems, H. M. G.; Wolfe, L.; Woolford, A. J. A.; Wu, Z.; Yan, H.; Kerns, J. K.; Davies, T. G., Structure-Activity and StructureConformation Relationships of Aryl Propionic Acid Inhibitors of the Kelch-like ECH-Associated Protein 1/Nuclear Factor Erythroid 2-Related Factor 2 (KEAP1/NRF2) Protein-Protein Interaction. J. Med. Chem. 2019, 62, 4683-4702.

(19) (a) Halpern, J., Free radical mechanisms in organometallic and bioorganometallic chemistry. Pure Appl. Chem. 1986, 58, 575-584. (b) Isayama, S.; Mukaiyama, T., A New Method for Preparation of Alcohols from Olefins with Molecular Oxygen and Phenylsilane by the Use of Bis(acetylacetonato)cobalt(II). Chem. Lett. 1989, 18, 1071-1074. (c) Eisenberg, D. C.; Norton, J. R., Hydrogen-Atom Transfer Reactions of Transition-Metal Hydrides. Isr. J. Chem. 1991, 31, 55-66. (d) Waser, J.; Gaspar, B.; Nambu, H.; Carreira, E. M., Hydrazines and Azides via the Metalcatalyzed Hydrohydrazination and Hydroazidation of Olefins. $J$. Am. Chem. Soc. 2006, 128, 11693-11712. (e) Choi, J.; Tang, L.; Norton, J. R., Kinetics of hydrogen atom transfer from $\left(\mathrm{h}^{5}-\right.$ $\left.\mathrm{C}_{5} \mathrm{H}_{5}\right) \mathrm{Cr}(\mathrm{CO})_{3} \mathrm{H}$ to various olefins: influence of olefin structure. $J$. Am. Chem. Soc. 2007, 129, 234-240. (f) Ishikawa, H.; Colby, D. A.; Seto, S.; Va, P.; Tam, A.; Kakei, H.; Rayl, T. J.; Hwang, I.; Boger, D. L., Total Synthesis of Vinblastine, Vincristine, Related
Natural Products, and Key Structural Analogues. J. Am. Chem. Soc. 2009, 131, 4904-4916. (g) King, S. M.; Ma, X.; Herzon, S. B., A Method for the Selective Hydrogenation of Alkenyl Halides to Alkyl Halides. J. Am. Chem. Soc. 2014, 136, 6884-6887. (h) Kuo, J. L.; Hartung, J.; Han, A.; Norton, J. R., Direct Generation of Oxygen-Stabilized Radicals by $\mathrm{H} \cdot$ Transfer from Transition Metal Hydrides. J. Am. Chem. Soc. 2015, 137, 1036-1039. (i) Crossley, S. W.; Obradors, C.; Martinez, R. M.; Shenvi, R. A., $\mathrm{Mn}-, \mathrm{Fe}-$, and Co-Catalyzed Radical Hydrofunctionalizations of Olefins. Chem. Rev. 2016, 116, 8912-9000. (j) Obradors, C.; Martinez, R. M.; Shenvi, R. A., $\mathrm{Ph}(i-\mathrm{PrO}) \mathrm{SiH}_{2}$ : An Exceptional Reductant for Metal-Catalyzed Hydrogen Atom Transfers. J. Am. Chem. Soc. 2016, 138, 4962-4971. (k) Lo, J. C.; Kim, D.; Pan, C. M.; Edwards, J. T.; Yabe, Y.; Gui, J.; Qin, T.; Gutierrez, S.; Giacoboni, J.; Smith, M. W.; Holland, P. L.; Baran, P. S., FeCatalyzed C-C Bond Construction from Olefins via Radicals. $J$. Am. Chem. Soc. 2017, 139, 2484-2503. (1) Green, S. A.; Crossley, S. W. M.; Matos, J. L. M.; Vásquez-Céspedes, S.; Shevick, S. L.; Shenvi, R. A., The High Chemofidelity of Metal-Catalyzed Hydrogen Atom Transfer. Acc. Chem. Res. 2018, 51, 2628-2640. (m) Shevick, S. L.; Obradors, C.; Shenvi, R. A., Mechanistic Interrogation of $\mathrm{Co} / \mathrm{Ni}-\mathrm{Dual}$ Catalyzed Hydroarylation. J. Am. Chem. Soc. 2018, 140, 12056-12068. (n) Wang, Y. Y.; Bode, J. W., Olefin Amine (OLA) Reagents for the Synthesis of Bridged Bicyclic and Spirocyclic Saturated $N$-Heterocycles by Catalytic Hydrogen Atom Transfer (HAT) Reactions. J. Am. Chem. Soc. 2019, 141, 9739-9745. (o) Zhou, X. L.; Yang, F.; Sun, H. L.; Yin, Y. N.; Ye, W. T.; Zhu, R., Cobalt-Catalyzed Intermolecular Hydrofunctionalization of Alkenes: Evidence for a Bimetallic Pathway. J. Am. Chem. Soc. 2019, 141, 7250-7255. (p) Shevick, S. L.; Wilson, C. V.; Kotesova, S.; Kim, D.; Holland, P. L.; Shenvi, R. A., Catalytic hydrogen atom transfer to alkenes: a roadmap for metal hydrides and radicals. Chem. Sci. 2020. (q) Yao, C.; Wang, S.; Norton, J.; Hammond, M., Catalyzing the Hydrodefluorination of $\mathrm{CF}_{3}$-Substituted Alkenes by $\mathrm{PhSiH}_{3}$. $\mathrm{H} \bullet$ Transfer from a Nickel Hydride. J. Am. Chem. Soc. 2020, 142, 4793-4799. (r) Wu, B.; Zhu, R., Radical Philicity Inversion in Co- and Fe-Catalyzed Hydrogen-Atom-Transfer-Initiated Cyclizations of Unsaturated Acylsilanes. ACS Catal. 2020, 10, 510-515. (s) Kattamuri, P. V.; West, J. G., Hydrogenation of Alkenes via Cooperative Hydrogen Atom Transfer. J. Am. Chem. Soc. 2020, 142, 19316-19326.

(20) (a) Shigehisa, H.; Aoki, T.; Yamaguchi, S.; Shimizu, N.; Hiroya, K., Hydroalkoxylation of Unactivated Olefins with Carbon Radicals and Carbocation Species as Key Intermediates. $J$. Am. Chem. Soc. 2013, 135, 10306-10309. (b) Shigehisa, H.; Koseki, N.; Shimizu, N.; Fujisawa, M.; Niitsu, M.; Hiroya, K., Catalytic Hydroamination of Unactivated Olefins Using a Co Catalyst for Complex Molecule Synthesis. J. Am. Chem. Soc. 2014, 136, 13534-13537. (c) Shigehisa, H., Functional Group Tolerant Markovnikov-Selective Hydrofunctionalization of Unactivated Olefins Using a Cobalt Complex as Catalyst. Synlett 2015, 26, 2479-2484. (d) Shigehisa, H.; Ano, T.; Honma, H.; Ebisawa, K.; Hiroya, K., Co-Catalyzed Hydroarylation of Unactivated Olefins. Org. Lett. 2016, 18, 3622-3625. (e) Shigehisa, H.; Hayashi, M.; Ohkawa, H.; Suzuki, T.; Okayasu, H.; Mukai, M.; Yamazaki, A.; Kawai, R.; Kikuchi, H.; Satoh, Y.; Fukuyama, A.; Hiroya, K., Catalytic Synthesis of Saturated Oxygen Heterocycles by Hydrofunctionalization of Unactivated Olefins: Unprotected and Protected Strategies. J. Am. Chem. Soc. 2016, 138, 10597-10604. (f) Date, S.; Hamasaki, K.; Sunagawa, K.; Koyama, H.; Sebe, C.; Hiroya, K.; Shigehisa, H., Catalytic Direct Cyclization of Alkenyl Thioester. ACS Catal. 2020, 10, 2039-2045. (g) Ebisawa, K.; Izumi, K.; Ooka, Y.; Kato, H.; Kanazawa, S.; Komatsu, S.; Nishi, E.; Shigehisa, H., Catalystand Silane-Controlled Enantioselective Hydrofunctionalization of Alkenes by Cobalt-Catalyzed Hydrogen Atom Transfer and Radical-Polar Crossover. J. Am. Chem. Soc. 2020, 142, 13481- 
13490. (h) Nagai, T.; Mimata, N.; Terada, Y.; Sebe, C.; Shigehisa, H., Catalytic Dealkylative Synthesis of Cyclic Carbamates and Ureas via Hydrogen Atom Transfer and Radical-Polar Crossover. Org. Lett. 2020, 22, 5522-5527.

(21) (a) Touney, E. E.; Foy, N. J.; Pronin, S. V., Catalytic Radical-Polar Crossover Reactions of Allylic Alcohols. J. Am. Chem. Soc. 2018, 140, 16982-16987. (b) Discolo, C. A.; Touney, E. E.; Pronin, S. V., Catalytic Asymmetric Radical-Polar Crossover Hydroalkoxylation. J. Am. Chem. Soc. 2019, 1752717532. (c) Huang, G.; Ke, M.; Tao, Y.; Chen, F., Specific ZSelectivity in the Oxidative Isomerization of Allyl Ethers to Generate Geometrically Defined Z-Enol Ethers Using a Cobalt(II)(salen) Complex Catalyst. J. Org. Chem. 2020, 85, 5321-5329. (d) Vrubliauskas, D.; Vanderwal, C. D., CobaltCatalyzed Hydrogen-Atom Transfer Induces Bicyclizations that Tolerate Electron-Rich and Electron-Deficient Intermediate Alkenes. Angew. Chem. Int. Ed. 2020, 59, 6115-6121. (e) Yahata, K.; Kaneko, Y.; Akai, S., Cobalt-Catalyzed Intermolecular Markovnikov Hydroamination of Nonactivated Olefins: $\mathrm{N}_{2}-$ Selective Alkylation of Benzotriazole. Org. Lett. 2020, 22, 598603.
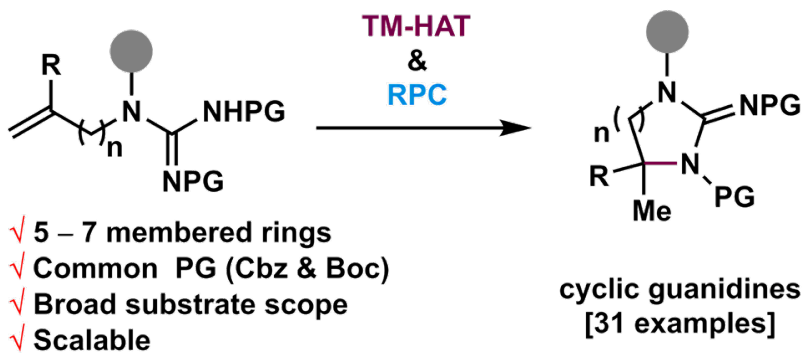

cyclic guanidines [31 examples] 